\title{
MOBILE-FRIENDLY WEBSITES: AN ANALYSIS OF WEBSITES OF FLAGSHIP UNIVERSITIES IN THE UNITED STATES
}

\author{
Kamal Hingorani, Alabama State University, khingorani@alasu.edu \\ Bob McNeal, Alabama State University,bobmcneal@alasu.edu \\ Jorja Bradford, Alabama State University,jbradford@alasu.edu
}

\begin{abstract}
This study discusses the technology used by flagship universities to redesign their websites because of internet users increased use of mobile devices. As of April 2016, ninety percent of these Universities have already made their website mobile-friendly using responsive web design. Responsive web design (RWD) is explained with examples. The technology infrastructure that supports $R W D$ is identified and explained. The use, by the 50 flagship universities, is provided in graphical format. Examples of different content approaches to meet mobile requirements are described with examples of university websites that focus on current and future stakeholders. The impact of RWD and new web development technology and the fact that MIS education needs to change to meet this challenge are also discussed.
\end{abstract}

Keywords: Flagship Universities, Information Technology (IT), Responsive Web Design, Mobile Devices, IT Infrastructure, JavaScript Libraries, Webserver Software, Content Management Software (CMS)

\section{INTRODUCTION}

Internet users no longer rely on a desktop and wired connection to access the Internet due to the penetration of smart phone and $4 \mathrm{G}$ wireless networks; more users are accessing the web through their mobile devices, even in developing countries (Anonymous, March - April 2015, Kim, November 2012). Social media sites such as Facebook, Twitter, and Instagram, have also played a major role in increasing mobile web traffic. Over half of LinkedIn traffic (61\%) is now mobile (Anonymous, Linkedin Announces First Quarter 2016 Results, 2016), while Google has recently reported more than half of its searches, in at least 10 countries, are derived from a mobile device (Anonymous, /itsofficial-google-says-more-searches-now-on-mobile-than-on-desktop-220369, May). The Daily Active Users (DAU) on Facebook for March 2016 were 1.09 billion, an increase of 16\% year-over-year while the Mobile DAUs were 989 million $(90 \%$ of total) for the same month, an increase of $24 \%$ year-over-year (Anonymous, investornews/press-release-details/2016/Facebook-Reports-First-Quarter-2016-Results-and-Announces-Proposal-for-NewClass-of-Stock/default.aspx, 2016).

Most businesses and social media started their web presence with a website designed for the desktop (E.g., http://www.facebook.com). As the volume of mobile device traffic increased, the difference in PC and mobile device access became more apparent. For example, Gafni identified barriers such as device size and screen size, small keyboards, and connection issues (Gafni, 2013). Another study suggested that developers focus on presentation (Hinman, 2008). At first, separate sites optimized for the mobile devices were created such as http://m.facebook.com. Over the last few years, a new approach-responsive web design as a one-website solution for multiple device types has gained traction. Figures 1 through 3 below show the difference in the two approaches the Boston Globe uses a single responsive website while the New York Times has two sites - one for the desktop and the other for mobile devices. 


\section{Issues in Information Systems \\ Volume 17, Issue II, pp. 17-24, 2016}

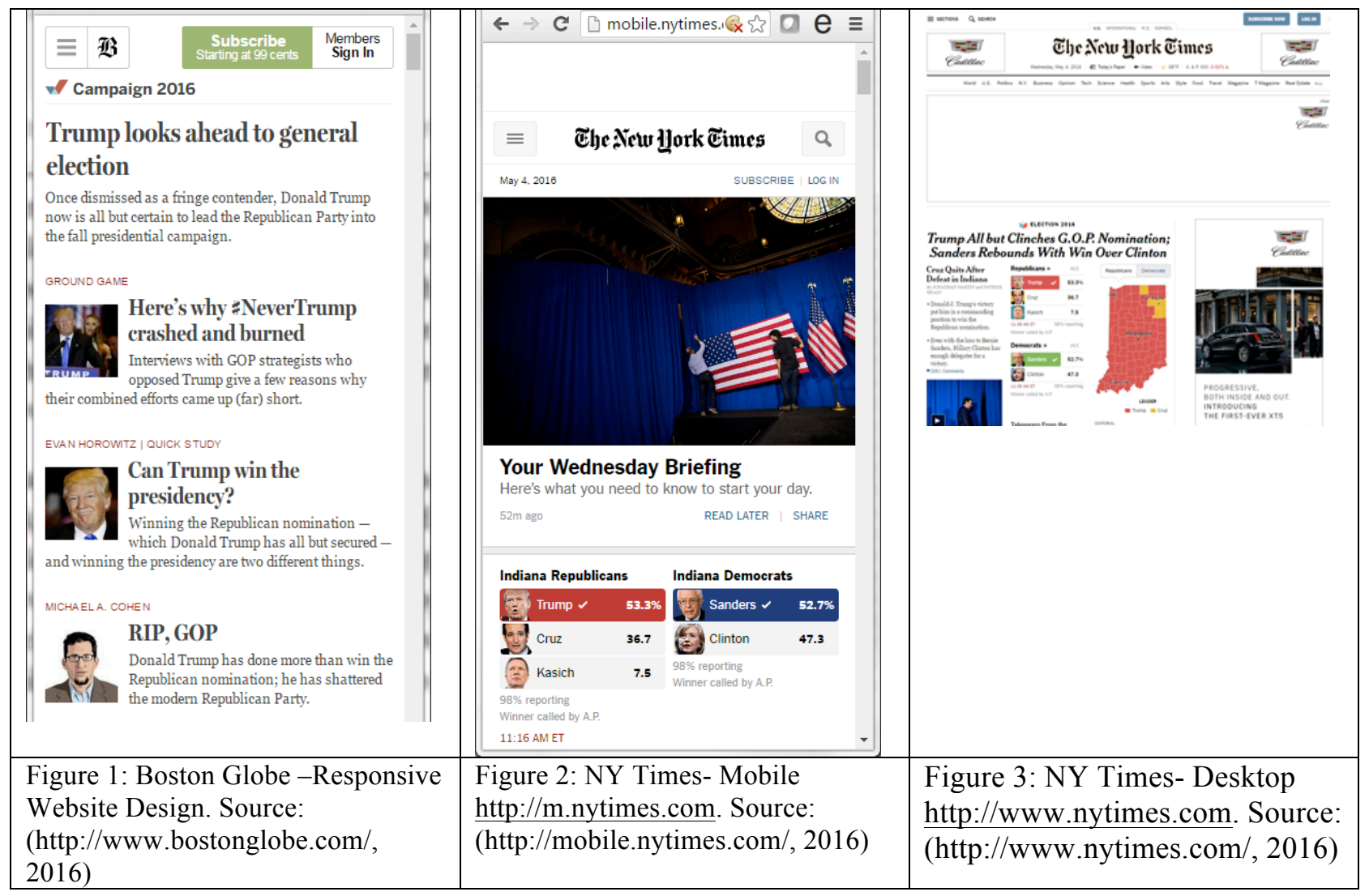

\section{RESPONSIVE WEB DESIGN}

Responsive web design (RWD) was first described in a website article by Ethan Marcotte (Resonsive Web Design, 2016). It is is an approach to web design in which a site is designed to provide an optimal viewing experience, easy reading and navigation with minimum resizing, panning, and scrolling - across a wide range of devices (from desktop computer monitors to smart phones) (Anonymous, /its-official-google-says-more-searches-now-onmobile-than-on-desktop-220369, May) (Marcotte, 2010). This approach overcomes the weaknesses of pixel-perfect web design, which produced web pages that were the same as a magazine page. A responsive website is device independent and the layout of the website is based on a flexible, fluid grid that adapts to different devices by using CSS (I.e., currently CSS3) media queries. (Kim B. , 2013)

In a responsive website, on a phone, users would see content shown in a single column view; a tablet might show the same content in two columns and the same content on the desktop can be seen in four columns. Responsive web design is recommended by Google because it does not have to crawl multiple pages (Marcotte, 2010). Research testing the top 10,000 websites for responsive indicators done in January 2014 showed roughly $12 \%$ of these sites were responsive, a ratio that was fairly consistent across the top 100, 1,000 and 10,000 sites (/rwd-ratio-in-top100000-websites-refined/, n.d.). However, Social Media site such as Facebook and Twitter continue to use separate URL for their mobile and desktop sites. The benefit of this approach is isolation of the development environment, which allows the developer to optimize code and features applicable to specific audiences (E.g., mobile or desktop browser). 


\section{TECHNOLOGIES SUPPORTING RESPONSIVE WEB DESIGN}

\section{Responsive Navigation Bar}

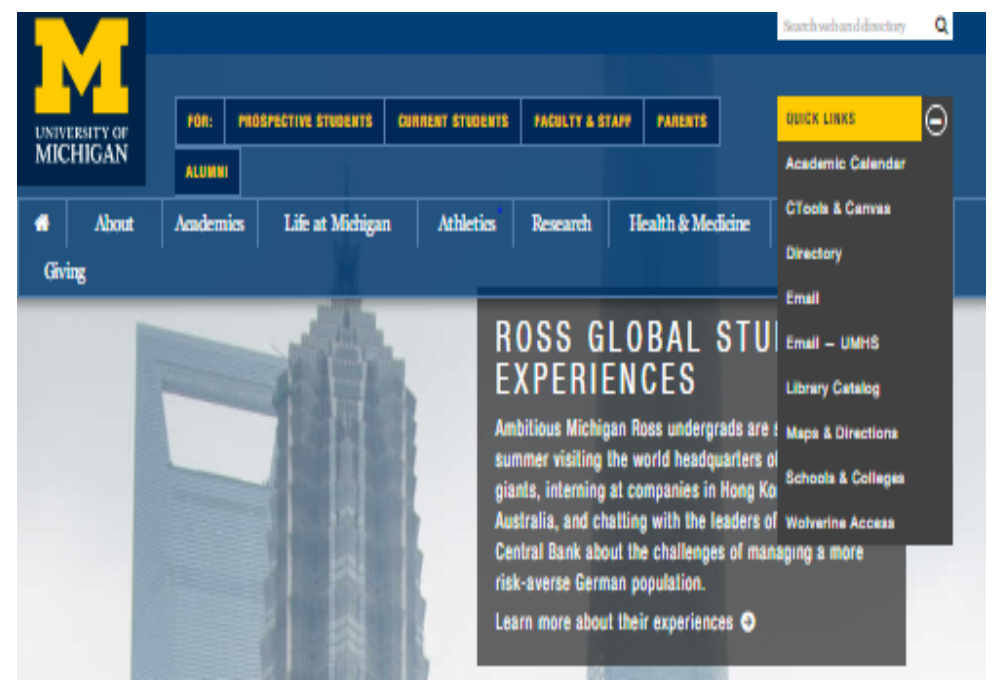

Figure 4. University of Michigan example of the use of a Hamburger Menu. Source: www.umich.edu

One of the important elements of RWD is the hamburger menu. Figure 4 shows the use of a "Hamburger" menu on the University of Michigan website. It is referred to as a "hamburger" because it looks roughly like a bun-meat-bun sandwich. When the web page is displayed on a mobile screen, individual navigation items are consolidated under a single button, which is called a hamburger menu. The hamburger menu is now built into every major front-end framework such as JQuery, Bootstrap, and WordPress. All new sites make use of the Hamburger menu.

\section{JavaScript Libraries}

In the age of open source developers and the GitHub revolution, a number of new and exciting JavaScript and CSS libraries have been created, shared and used for developing responsive websites. Some of the libraries that are most commonly used on RWD are presented next.

\section{JQuery Mobile}

JQuery Mobile is a HTML5-based user interface system designed to create responsive websites and apps that are accessible on all smartphone, tablet and desktop devices. It uses the jQuery and jQuery UI foundation, and offers Ajax navigation with page transitions, touch events, and various widgets (http://jquerymobile.com/, n.d.).

\section{Modernizr}

Modernizr is a JavaScript library that detects HTML5 and CSS3 features in the user's browser. Modernizr runs quickly on page load to detect features; it then creates a JavaScript object with the results, and adds classes to the html element. YepNope.js, used for conditional loading of external .js and .css resources, is supported, but not recommended and has recently been added to Modernizr (https://www.modernizr.com/, n.d.). 


\section{Bootstrap}

Bootstrap was initially developed by former Twitter employees Mark Otto and Jacob Thornton, as an internal development tool to improve consistency and efficiency. It was later released as an open source project on GitHub and is today the most popular repository on the platform. Bootstrap contains global CSS settings with built-in components and extensible classes in the form of typography, navigation, buttons and much more. Bootstrap is the fastest growing JavaScript library and is being widely used in all new website development (what-is-bootstrap/, n.d.). The popularity of Bootstrap has led to the development of editors and builders that make it easier to prototype test and build responsive websites. Although each editor is different, all feature some form of drag and drop functionality using Bootstrap's huge library of components (what-is-bootstrap/, n.d.).

\section{Zerb Foundation}

This framework is an open source project on GitHub and is popular with developers. Some developers believe that this framework offers better features than Bootstrap (responsive-comparison/, 2015).

\section{Web Fonts}

Typography is one of the most important aspects of responsive web design. Optimizing fonts for mobile devices is necessary if the content is to be displayed across many screen sizes. Web fonts are those not installed on a computer, but loaded from a web server. They are displayed by using the CSS3@font-face declaration and are supported by all the major web browsers. Of the many web fonts available, Adobe's TypeKit and Google's Font API are the most popular.

\section{FLAGSHIP UNIVERSITIES IN THE UNITED STATES}

Each state in the U.S. touts a premier university as the flagship of its publicly funded higher education system. They are generally the state's largest producer of undergraduate education, graduate education and scholarly output and, relative to other state colleges and universities, receive larger budgets and funding priorities under discretionary allocations (Sav, 2011). Of the 50 flagship universities, only five universities had not adopted the responsive web design for their websites (E.g., University of Delaware, University of Hawaii at Manoa, University of North Dakota, University of Wyoming, and the University of Maryland: College Park). The University of Maryland's Robert H. Smith School of Business's new website has already adopted RWD.

\section{IT INFRASTRUCTURE AND TECHNOLOGIES USED ON WEBSITES}

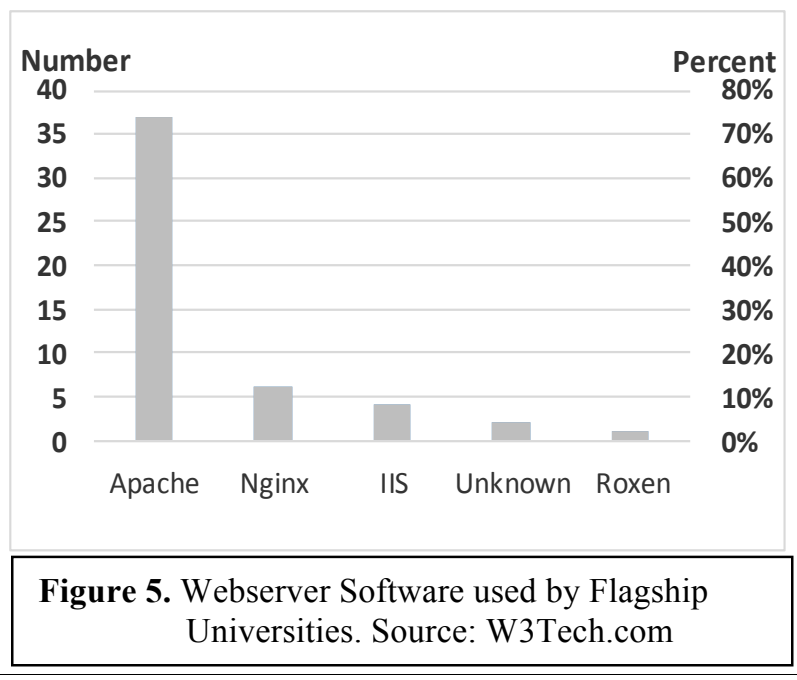


Webserver Software- W3Tech technology Surveys conducts numerous studies investigating the use of different types of technology used for building and operating websites. The data is analyzed and published in summary form and reports can be purchased.

The results of their May 2016 webserver analysis detected different webserver software (Figure 5) adopted by 48 universities. Apache was adopted by $74 \%$ of the universities while Nginx was used by $12 \%$ of the universities. An analysis of all websites done by W3 Technology Survey found that usage of Apache, Nginx and IIS were 52.7\%, $29.9 \%$, and $12.0 \%$ respectively (technologies/overview/web_server/all, 2016).

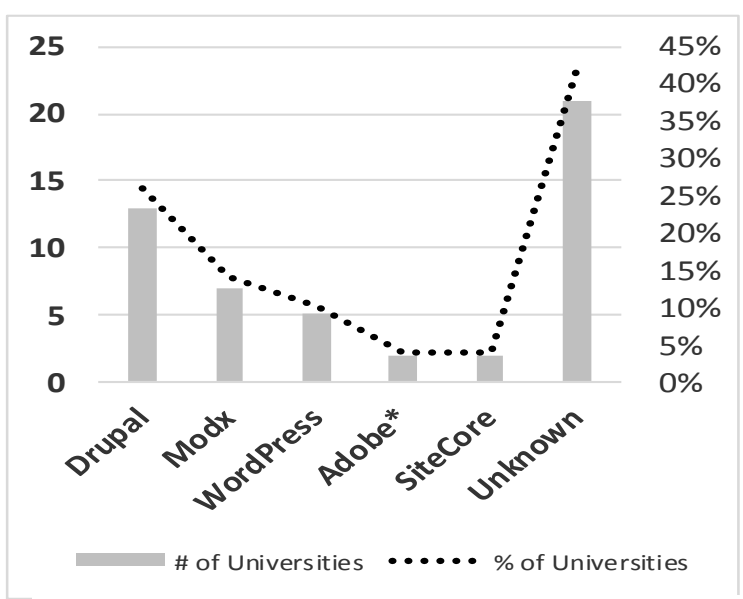

Figure 6. CMS software used by Flagship Universities. Source: W3Tech.com

Content Management Software (CMS) - W3tech recently identified Content Management Software adopted by 29 universities. Drupal, Modx, and WordPress were the most used as shown in Figure 6. Two of the websites adopted a relatively new product - Adobe Experience Manager. WordPress, Joomla, Drupal, and Magento were the top ranked CMS software in W3Tech's Content Management Survey (technologies/overview/web_server/all, 2016).

JavaScript Libraries- JQuery was used by all the websites. Modernizr and Bootstrap were adopted by $32 \%$ and $28 \%$ of the universities. JQuery (70\%), Bootstrap (12\%), Modernizr (10\%) were the most widely used JavaScript libraries in the W3 Technology Survey (http://jquerymobile.com/, n.d.).

\section{Font Libraries}

Google Font API was the most popular web font library in another W3Tech study with 22 universities using it, followed by Fontawesome and Typekit, which were used by four universities each.

\section{Traffic Analysis Tools}

Most of the websites made use of Google Analytics was used by 55\% of the websites for analyzing traffic. Other analysis tools included Chartbeat, Cragyegg, Mediaelement.js, Optimizely, Kissmetrics, Piwik Analytics, and Webtrends (technologies/overview/web_server/all, 2016).

\section{APPROACHES TO LAYOUT FOR THE MOBILE DEVICE}

Most universities that have adopted RWD had the University logo, a hamburger menu, and search as their top element. Some universities had a separate search while others had it inside the hamburger menu. The second element in most websites was a carousel with three or more images. 
There were different approaches to the third element on the mobile device. Some universities (E.g., University of Colorado: Figure 7) targeted current stakeholders using Campus News and Events. Another approach (E.g., University of Alabama: Figure 8) targeted future stakeholders with Undergraduate majors and Graduate programs.

The long and skinny canvas on mobile devices provides a large canvas area (lengthwise) to a designer. However, across the fifty universities there was no consistent approach to the elements that were displayed, or how they were organized. For example, some universities wasted space on their mobile canvas by not making use of the hamburger menu or by displaying their logos and menus as separate elements. Some universities had more than one menu on their mobile display.

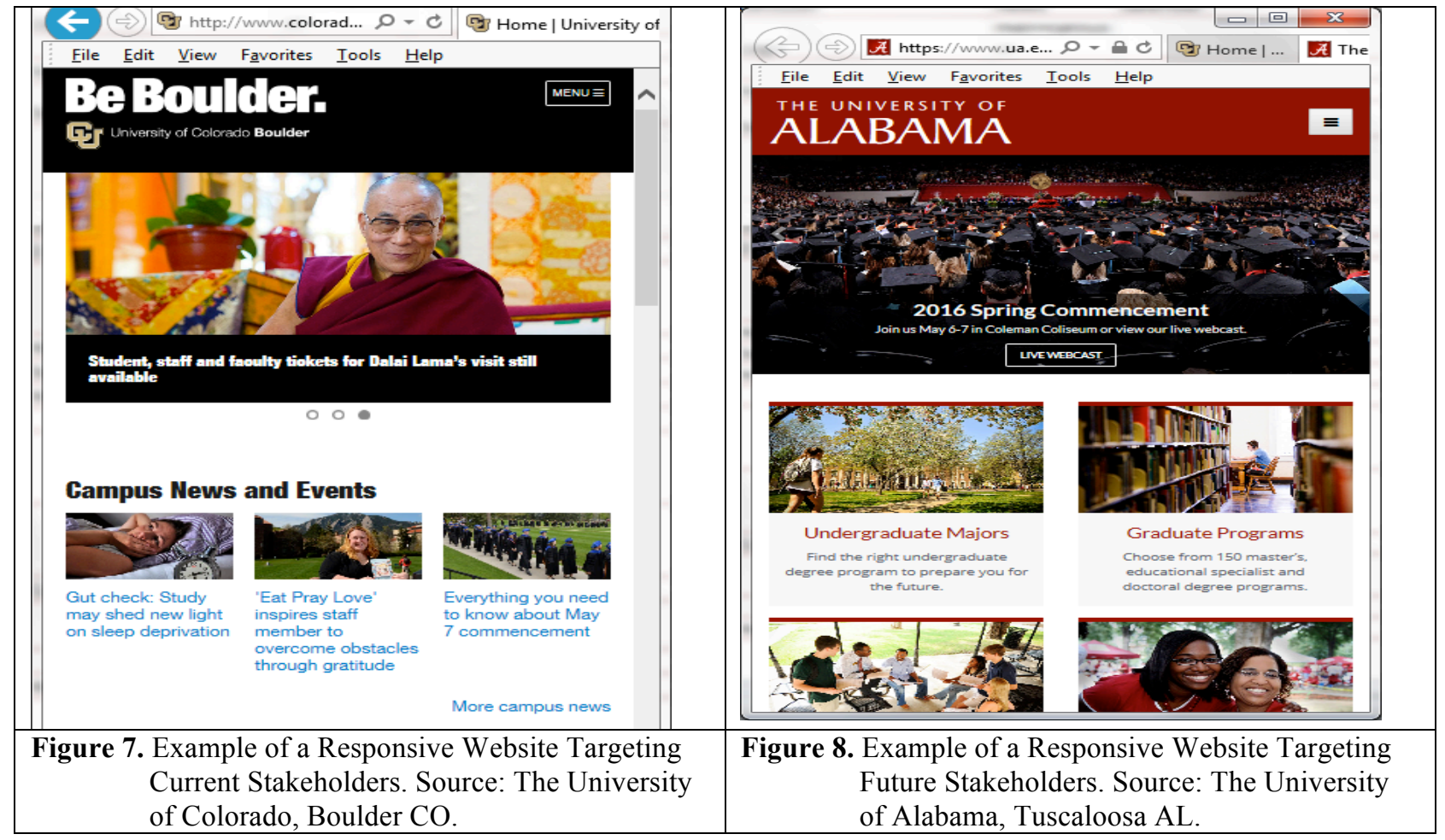

\section{CONCLUSIONS AND AREAS FOR FUTURE RESEARCH}

Universities websites are generally large, complex, and very difficult to manage. It is therefore heartening to learn that in spite of severe organizational challenges, including limited budgets; most flagship universities across the nation have redesigned their websites to cater to the increasingly larger traffic from mobile devices. Most universities have also reviewed the contents during their redesign.

Many large private universities have also redesigned their websites using the RWD approach. This is however not true for most of the middle-tier and small universities which do not have the resources to be the early adopters of this new technology. The flagship universities generally set the standards for other universities in a state and it can be safely assumed that the smaller universities will quickly follow the lead.

This paper again raises the perennial question- How can the MIS/IS curriculum be made relevant? A course on Web development has become essential in the MIS curriculum. However, teaching a Web development course is challenging because of rapidly changing technologies and the diverse background of the students. This paper 


\section{Issues in Information Systems}

Volume 17, Issue II, pp. 17-24, 2016

presents the web technologies that have been adopted by flagship universities on their websites. Web development courses in MIS programs should keep pace with the technologies that have been adopted by the university IT departments. Concepts such as RWD require higher level programming skills, but frameworks such as bootstrap and the availability of web editors provide new opportunities for teaching difficult concepts in the classroom.

\section{REFERENCES}

Anonymous. (2016, May 4). events-and-news/corporate-press-releases/press-release-details/2016/LinkedInAnnounces-First-Quarter-2016-Results/default.aspx. Retrieved May 4, 2016, from https://investors.linkedin.com/: https://investors.linkedin.com/events-and-news/corporate-pressreleases/press-release-details/2016/LinkedIn-Announces-First-Quarter-2016-Results/default.aspx

Anonymous. (2016, May 4). investor-news/press-release-details/2016/Facebook-Reports-First-Quarter-2016Results-and-Announces-Proposal-for-New-Class-of-Stock/default.aspx. Retrieved from https://investor.fb.com: https://investor.fb.com/investor-news/press-release-details/2016/Facebook-ReportsFirst-Quarter-2016-Results-and-Announces-Proposal-for-New-Class-of-Stock/default.aspx

Anonymous. (March - April 2015). The life-changing side of mobile communications. Information Management Journal. (49.2), 10.

Anonymous. (May, 4 2016). /its-official-google-says-more-searches-now-on-mobile-than-on-desktop-220369. Retrieved from http://searchengineland.com: http://searchengine.com/its-official-google-says-moresearches-now-on-mobile-than-on-desktop-220369

Gafni, R. a. (2013). Exploring the addition of mobile access to a healthcare services website. Issues in Informing Science \& Information Technology. 10 (Annual 2013), 163 - 174.

Hinman, R. S. (2008). They call it "surfing" for a reason: Identifying mobile Internet needs through PC deprivation. Proceedings of the 26th international conference on Human factors in computing systems, 2195-2208. New York, USA: ACM. (pp. 2195 - 2208). Chicago: ACM.

JQueryMobile.com, (n.d.). Retrieved from http://jquerymobile.com/: http://jquerymobile.com/

NYTimes. (2016, May 4). Retrieved from http://mobile.nytimes.com/: http://mobile.nytimes.com/

Bostonglobe.com. (2016, May 4). Retrieved from http://www.bostonglobe.com/: http://www.bostonglobe.com/

NY Times.com. (2016, May 4). Retrieved from http://www.nytimes.com/: http://www.nytimes.com/

Modernizr.com. (n.d.). Retrieved from https://www.modernizr.com/: https://www.modernizr.com/

Kim, B. (2013). Responsive Web Design, Discoverability, and Mobile Challenge. Chicago IL: American Library Association.

Kim, S. a. (November 2012). Consumer preferences for mobile Internet: a comparative cross-national mixed methods study. Social Behavior and Personality: An International Journal. (40.10), 1695 - 1711.

Marcotte, E. (2010, May 25). Responsive Web Design/article\%20/responsive-web-design. Retrieved from http://alistapart.com: http://alistapart.com/article\%20/responsive-web-design 


\section{Issues in Information Systems}

Volume 17, Issue II, pp. 17-24, 2016

Responsive Web Design. (2010, May 25). Retrieved from http://alistapart.com: http://alistapart.com/article\%20/responsive-web-design

Responsive-comparison/. (2015, December 7). Retrieved from www.vermilion.com: http://www.vermilion.com/responsive-comparison/

Rwd-ratio-in-top-100000-websites-refined. (n.d.). Retrieved from http://www.guypo.com: http://www.guypo.com/rwd-ratio-in-top-100000-websites-refined/

Sav, G. (2011). Cost Efficiencies and Rankings of Flagship Universities. American Journal of Economics and Business Administration, 596 - 603.

Technologies/overview/web_server/all. (2016, May 9). Retrieved from https://w3techs.com: https://w3techs.com/technologies/overview/web_server/all

What-is-bootstrap. (n.d.). Retrieved from https://bootstrapbay.com/blog/: https://bootstrapbay.com/blog/what-isbootstrap/ 